\title{
Barriers on access to and use of adolescent health services in Ghana
}

\author{
Aaron Asibi Abuosi and Emmanuel Anongeba Anaba \\ Department of Public Administration and Health Services Management, \\ Business School, University of Ghana, Accra, Ghana
}

\begin{abstract}
Purpose - The purpose of this paper is to explore perceived barriers to accessing and using adolescent health services in Ghana.

Design/methodology/approach - The study was a qualitative study adopting a case study design. In total, 24 adolescents were recruited from four adolescent health facilities in Tema, a suburb of Ghana, using convenient sampling. In-depth interviews with respondents were conducted coupled with the taking of field notes and personal observations. Data collection took place between January and May 2017. Data were transcribed, managed and coded for themes. Thematic analysis was guided by Braun and Clarke's (2006) Framework.

Findings - The findings of this study revealed that majority of the respondents were females (54 percent) older adolescents (above 15 years (60 percent), students (79 percent)), had junior high school education and stayed with their biological parent(s) (70 percent). Adolescents in this study perceived four main barriers that restrict their access to or use of adolescent health services. The barriers were found at the facility level, provider level, community level and personal level.

Originality/value - The findings of this study provide evidence-based information for planning adolescent health care interventions that would improve adolescents' access to and use of health services in Ghana.
\end{abstract}

Keywords Barriers, Adolescent, Adolescent health services, Ghana

Paper type Research paper

\section{Introduction}

Adolescents (10-19 years) are the future leaders of our society and an untapped human resource. About one-fifth (more than 1.2bn) of the global population are adolescents, and many of the world's adolescents live in developing nations[1,2]. Adolescents are perceived to be healthy, however, they are vulnerable and exposed to many health risks leading to premature deaths[2-5]. In 2015, about $1.3 \mathrm{~m}$ adolescents died globally from causes that could have been prevented[2]. Over two-thirds of these deaths occurred in low- and middle-income countries (LMICs) with 45 percent from Africa[6]. According to Neal et al.[7], approximately $16 \mathrm{~m}$ girls aged $15-19$ years and $2.5 \mathrm{~m}$ girls under 16 years give birth each year in developing regions. About 3m girls aged 15-19 years undergo unsafe abortions every year[8]. Moreover, about $2 \mathrm{~m}$ adolescents are living with human immune virus (HIV) globally[9], and over 41 percent of new HIV infections in every year occur among adolescents[2].

(c) Aaron Asibi Abuosi and Emmanuel Anongeba Anaba. Published in Journal of Health Research. Published by Emerald Publishing Limited. This article is published under the Creative Commons Attribution (CC BY 4.0) licence. Anyone may reproduce, distribute, translate and create derivative works of this article (for both commercial and non-commercial purposes), subject to full attribution to the original publication and authors. The full terms of this licence may be seen at http://creative commons.org/licences/by/4.0/legalcode

The researchers declare that there is no conflict of interest. This research received no specific grant from any funding agency in the public, commercial or not-for-profit sectors. The researchers are thankful to the management members of Tema Metropolitan Health Directorate for their warm reception and support during the data collection. The researchers also thank all adolescents who participated in the study.
Access to and use of adolescent health

Received 9 October 2018 Revised 29 October 2018

7 November 2018

8 November 2018

Accepted 13 November 2018 
JHR

33,3

Adolescents' health, well-being and development can be promoted through access to adolescent health services[2]. However, many adolescents do not seek health care when they should[10-12]. Prior studies show that adolescents across the globe encounter barriers such as difficulty making an appointment, long waiting hours, negative provider attitudes, lack of privacy and confidentiality, social-cultural norms and taboos, the high cost of care and stigma among issues when accessing health services[2, 12-16]. In this regard, global health organisations such as the World Health Organization have urged member countries to adopt measures for making health care services accessible to adolescents[2].

In their quest to improve access to and use of adolescent health services, Ghana Health Services in collaboration with the Ministry of Health Ghana integrated adolescent health services into primary health care. Old adolescent health facilities also known as adolescent clinics (AC) were renovated coupled with the contraction of new ones, summing up to 212 ACs. Resources such as health information materials (books, flyers and leaflets), logistics and health care providers were distributed to the various $\mathrm{ACs}[17]$.

Despite these efforts, both the grey literature and anecdotal evidence show that unplanned pregnancies leading to school drop-out, childbirth complications and illegal abortions remains high among adolescents in Ghana. Moreover, substance abuse and HIV infection among adolescents remain as public health problems in Ghana[17-19]. For example, the study location (Tema Metropolis) recorded 641 and 609 adolescent pregnancies in 2015 and 2016, respectively. In 2016, 21 pregnant adolescents were tested HIV positive, while 63 unsafe or illegal abortions were reported[18].

In addition, a report of the Family Health Division of Ghana Health Service indicated that adolescents' access to appropriate health information has not improved significantly over time. Even though there has been an overall improvement in the utilisation of health care services, utilisation by adolescents remains low[17]. The report attributed these setbacks to barriers like poor provider attitudes, inadequate and poorly resourced adolescent health facilities, financial constraints and lack of parental support[17].

However, these claims have not been subjected to any scientific scrutiny. To the best of the authors' knowledge, no empirical study, neither qualitative nor quantitative, has been conducted in Ghana to shed light on these claims. Prior studies focused on adolescents' use and preference for sexual and reproductive health services[20,21], with no focus on barriers to accessing and using adolescent health services. However, having empirical evidence on barriers to accessing health care, especially from an adolescents' perspective, can inform adolescent health policies or interventions. Therefore, this study sought to explore perceived barriers to accessibility and utilisation of adolescent health services in Tema, a suburb of Ghana's capital city.

\section{Materials and methods \\ Study area}

The study was conducted in Tema Metropolis, an urban area located in the eastern part of Accra, Ghana's capital. It is the second largest populated district in the region after Accra Metropolis[22]. According to the 2010 Population and Housing Census, the metropolis has a population of 292,773 representing 7.3 percent of the region's total population[22]. Adolescents represent about 18.9 percent of the total population of the area[22]. At the time this study was conducted, the metropolis had only four AC located within public health facilities. Furthermore, the Tema Metropolis records high incidence of adolescent pregnancies, illegal abortions and HIV infections every year[18].

\section{Design, sampling and data collection}

The study was a qualitative study adopting a case study design. Respondents were selected from four ACs. In-depth interviews were conducted using an interview guide 
and a face-to-face approach at the ACs. Items on the interview guide were selected based on a review of the empirical literature with input from a senior researcher. The interview guide was tested in a pilot study comprising of ten adolescents and modified. The interview guide was made up of two main sections. The first section contained questions related to socio-demographic variables of the respondents. The second section asked questions related to perceived barriers to access and use of health services in the ACs. Inductive probing was adopted to solicit in-depth information that was not captured in the interview guide. Interviews were conducted by the second author, a trained graduate student. Notes were taken during the interview and respondents who were agreeable, were audio taped. The interviews ended when the researcher realized that respondents were not providing any new information. In all, 24 adolescent respondents were interviewed in four AC (Table I). Interviews were conducted using both English and Twi, a widely spoken local language in Ghana. Data collection was conducted between January and May 2017. Even though data collection lasted for five months, the quality of the data was not affected.

\section{Ethical consideration}

This study is an excerpt of a student thesis. During the time of the study, the institution was lenient with students regarding Ethical Review Board approval. However, ethical principles in research such as informed consent, voluntary participation, privacy and confidentiality among others were duly observed by first asking respondents to sign a consent form. Participation was purely voluntary and no participant was coerced or lured into participating. Respondents were assured of their confidentiality and data were destroyed after the final analysis. Also, respondents had the free will to opt-out at any stage of the interview. In addition, permission to conduct this study was granted by the Ghana Health Service, the mother institution of health care delivery in Ghana and the Metropolitan Health Directorate facility managers. Where possible, consent of parents or guardians was gained since respondents were adolescents.

\section{Data analysis}

Data were analysed using a thematic analysis approach. According to Maguire and Delahunt[23], this is the process of identifying patterns or themes within qualitative data. In this regard, Braun and Clarke's thematic analysis framework was adopted[24]. Audio recording in the local (Twi) language was translated into English by the first author (Emmanuel Anongeba Anaba). The second author (Aaron Asibi Abuosi) verified the transcripts by simultaneously comparing it with the audio. The transcripts and the field notes were read over severally by the authors to gain familiarisation with the data coupled with writing down initial impressions. Adopting an inductive approach, segments of each transcript was coded to identify key concepts. Coding was done manually and independently by the two authors. Afterwards, each code was compared, discussed and modified where necessary. The codes were critically examined and those that fitted were put into themes. The themes were then reviewed to ensure coherence between each theme and

\begin{tabular}{lcccccc}
\hline Number of adolescents recruited & January & February & March & April & May & Total \\
\hline Male & 2 & 1 & 3 & 3 & 2 & 11 \\
Female & 3 & 3 & 3 & 2 & 2 & 13 \\
Total & 5 & 4 & 6 & 5 & 4 & 24
\end{tabular}

Source: Field Survey (2017)
Access to and use of adolescent health 
JHR

33,3

200

\section{Results}

Socio-demographic information

The researchers selected both males and females to ensure that views of both genders were well represented. The majority of the respondents were older adolescents (above 15 years), students were mostly educated to junior high school level and stayed with their biological parents (Table II).

This section presents findings on barriers to using and accessing adolescent health services. Findings are presented based on the four main themes that emerged. These include barriers at the facility level, personal level, provider level and community level (Table III).

Facility-level barriers. Inadequate physical space and privacy. Adolescents in this study identified inadequate physical space and privacy as a facility-level barrier to using adolescent health services. Adolescents further indicated that the ACs were not spacious enough. To confirm this, the researcher observed that during a health talk session, some adolescents had to stand outside the room (AC) because of lack of space. Moreover, all the ACs were single rooms used for multiple purposes with the same room often used as a library and for consultation. These practices were associated with inconveniences such as inadequate privacy, overcrowding and poor ventilation:

The space at the adolescent clinic is too small, whenever we (adolescents) come in our numbers, like health talk days, there is always overcrowding. Sometimes we have no choice but to stand outside the room where you cannot even hear what the nurse is saying. Female, 14 years, student

\begin{tabular}{lc}
\hline Characteristic & Frequency \\
\hline Gender & \\
Male & 11 \\
Female & 13 \\
Age (years) & \\
$11-13$ & 6 \\
$14-16$ & 8 \\
$17-19$ & 10 \\
Education & \\
No education & 2 \\
Primary school and below & 4 \\
Junior high school & 12 \\
Secondary/Vocational & 6 \\
Occupation & \\
Schooling & 19 \\
Not schooling & 5 \\
Religion & \\
Christianity & 11 \\
Islam & \\
Traditional & 8 \\
Residential status & 5 \\
Stay with parent(s) & \\
Stay with non-parents & 17 \\
Source: Field data (2017) & 7
\end{tabular}

\section{Table II.}

Socio-demographic characteristics of the respondents the data associated. Finally, the themes were defined into main and sub-themes. Results were presented based on the main and sub-themes and verbatim quotations, as seen in the findings section of the paper, were chosen at random. 


\begin{tabular}{|c|c|c|c|}
\hline Main Themes & Sub-themes & Illustrative quotes & \\
\hline Facility-level barriers & $\begin{array}{l}\text { Inadequate physical space and } \\
\text { privacy } \\
\text { Inconvenient operating hours } \\
\text { Shortage of medicines and supplies }\end{array}$ & \multirow{3}{*}{$\begin{array}{l}{[\ldots] \text { when [adolescents] come in their numbers }} \\
{[\ldots] \text { there is overcrowding at the [clinic] }} \\
{[\ldots] \text { the [adolescent clinics] do not operate on }} \\
\text { weekends when [we] are at home } \\
{[\ldots] \text { the [nurses] at the }[\text { ACs] are rude to }} \\
\text { [adolescents] } \\
{[\ldots] \text { the [providers] attend to their friend first }} \\
{[\ldots] \text { before others }}\end{array}$} & $\begin{array}{r}\text { adolescent } \\
\text { health }\end{array}$ \\
\hline \multirow[t]{2}{*}{ Provider-level barriers } & \multirow{2}{*}{$\begin{array}{l}\text { Disrespect } \\
\text { Discrimination } \\
\text { Judgemental attitude }\end{array}$} & & 201 \\
\hline & & & \\
\hline $\begin{array}{l}\text { Community-level } \\
\text { barriers }\end{array}$ & $\begin{array}{l}\text { Lack of parental support } \\
\text { Negative perceptions }\end{array}$ & $\begin{array}{l}{[\ldots] \text { parents would not allow [adolescents] to }} \\
\text { visit the clinics }[\ldots]\end{array}$ & \multirow{5}{*}{$\begin{array}{r}\text { Table III. } \\
\text { Main themes, sub- } \\
\text { themes and } \\
\text { illustrative quotes } \\
\text { demonstrating } \\
\text { perceived barriers to } \\
\text { using and accessing } \\
\text { adolescent health } \\
\text { services }\end{array}$} \\
\hline & Peer influence & $\begin{array}{l}{[\ldots][\text { people }][\ldots] \text { thinks [adolescents] visit }[\ldots]} \\
\text { for condoms }[\ldots]\end{array}$ & \\
\hline Personal-level barriers & $\begin{array}{l}\text { Fear } \\
\text { Lack of information }\end{array}$ & $\begin{array}{l}\text { [...] [adolescents] do not know about the } \\
\text { [clinic], what [clinics] do [...] }\end{array}$ & \\
\hline & Financial challenges & $\begin{array}{l}\text { [...] [adolescents] are afraid of been chastised } \\
\text { by [providers] }\end{array}$ & \\
\hline \multicolumn{3}{|c|}{ Source: Field interviews (2017) } & \\
\hline
\end{tabular}

There is too much heat in the room (adolescent clinic). I wish they fix air conditioners or fans in the room to keep it cool for us (adolescents). Male, 19 years

Shortage of medicines and supplies. Adolescents perceived that resources like medicines and supplies were insufficient. They claimed that there were times they did not get prescribed drugs and supplies like condoms from the ACs. The adolescents emphasised that sometimes they had to buy supplies from pharmacies. Some adolescents added that they were not employed and therefore could not afford these commodities:

Some time ago I used to get drugs from the adolescent clinic for free. But, now I do not get the drugs for free. I have to buy from the drug store (community pharmacy), but I am a student and not working. Female, 19 years

The nurses tell us not to have sex without a condom. But sometimes, I can request for condoms and the nurses will tell me that it is finished. I do not feel happy to hear that, especially when I have a "match" (want to have sex). Male, 18 years

Inadequate resources. Also, adolescents perceived that the libraries of the ACs were poorly resourced. While some adolescents found it difficult to borrow the health information materials from the ACs, others stated that the information materials were few and not comprehensive. Entertainment facilities like games and televisions were also perceived to be lacking at the ACs:

We (adolescents) usually want to visit the library to read, but the books are few and the chairs and tables are not many. Also, the books in the library are very old, dirty and scanty, they do not look attractive. The hospital (AC) should buy new books and more furniture for adolescents who want to come to the clinic to read. Female, 18 years

The adolescent clinic is too boring. There are no entertainment facilities at the clinic. Sometimes I want to come to the clinic to play games or watch adolescent health videos, but some of these things discourage me. Male, 13 years

Inconvenient operating hours. Inconvenient operating hours also emerged as a facility-level barrier to accessing adolescent health services. Adolescents indicated that the ACs operated between 8 a.m. and 2 p.m. on weekdays only and did not operate on weekends and public holidays. Some adolescents felt that the operating hours 
were not convenient for them, because they were students and were in school during those hours:

The nurses who work at the adolescent clinic come in the morning and close in the afternoon. The adolescent clinic is not opened on holidays and weekends. I am a student and cannot leave my classes (studies) and visit the adolescent clinic. Male, 15, student

I am free on weekends only but the clinic is not opened on weekends, so how do I come here? I think they should do something about this or else some of us cannot visit the clinic. The clinic [adolescent clinic] should operate on weekends and late afternoon, so that I can have access to services provided at the clinic. Female, 14 years, student

Long patient waiting time. Long patient waiting time was also found to be a key facilitylevel barrier, especially for pregnant adolescents. Some pregnant adolescents indicated that they had to go through the usual antenatal routine, such as health talks and taking of vital signs before they were separated and attended to by an adolescent health care professional. On average, a pregnant adolescent spent about $3 \mathrm{~h}$ to access antenatal care:

I stay far from the hospital (AC). If I (pregnant adolescent) want to go home early, I have to reach here (the facility) as early as 5:30 am in order to avoid long queues and unnecessary delays. This is because the pregnant women who visit this hospital are too many. Female, 18, pregnant

Community-level barriers. Lack of parental support. Some respondents expressed worries about the lack of parental support for them to access adolescent health services. They were afraid that their parents may punish them if they found out that they visited the AC:

I always want to come to the adolescent clinic but if my parents find out that I come to the clinic, they will beat me and warn me not to step foot here again. Because of that am always afraid to come to the adolescent clinic. Today, for instance, I was able to come here (AC) because they (parents) are not at home. Female, 14 years

My mum warned me not to visit the adolescent clinic because someone had told her that adolescents go there for condoms and abortions. Therefore, my parents will not allow me to come to the adolescent clinic, because they think I will become a "bad girl". I am able to come here (AC) today because my teacher accompanied me. Female, 15 years

Negative perceptions. Adolescents who accessed health care from the ACs were inevitably labelled or tagged with "bad names". Adolescents stated that community members perceived adolescents who visited the clinics as "bad" boys and girls. Some community members had the perception that adolescents visited the ACs for contraceptives and abortion services. Because Ghanaian society frowns upon premarital sex, adolescents who were afraid of being labelled as "bad" stayed away from the ACs:

People in this community think negative of adolescents who visit the AC. They think we come here to do abortion or collect condoms. Because of that, I do not want people to see me when am coming to the clinic. They may think am coming for a pregnancy test or an abortion and may call me a bad girl. Female, 18 years

Peer influence. Some adolescents experienced restrictions from friends and lovers when they tried visiting the $\mathrm{AC}$ for the first time. Some adolescent girls indicated that their boy lovers warned them not to visit the adolescent clinic:

I was a regular client of the adolescent clinic, but when I met my boyfriend (lover), he warned me not to visit the clinic anymore, because if people see me they will think am a bad girl. He even told me he will break up with me if I go contrary to his warning. Female, 18 years

When I wanted to visit the adolescent clinic for the first time, my friend warned me to stay away, because, someone from the community had told him that adolescents visit the clinic for sex education and contraceptives. Male 17 years 
Provider-level barriers. Disrespect for adolescents. Some adolescents were not comfortable with the attitudes of some health providers. Adolescents indicated that some of the health care providers did not respect their views and talked to them in a disrespectful manner:

Some of the nurses in the clinic are rude and disrespectful, especially to us, the pregnant adolescents. They do not respect our opinions. Also, they shout on us and call "names" (offensive word). This makes it difficult for me to ask them questions. Female, 17 years

Discrimination. Discrimination also emerged as a barrier to using adolescent health services.

Access to and use of adolescent health

Adolescents indicated that some of their colleagues were given preferential treatment. Moreover, some adolescents claimed that they were denied health care:

During my last antenatal visit, the nurse (health care provider) asked me to do a laboratory test, but my "boyfriend" did not get money for me to go for the laboratory result. The nurse refused to attend to me because my laboratory result was not available. Female, 17 and pregnant

The nurses in this facility (AC) are not fair at all. If you come early and your card (patient folder) is on top, someone who comes later and knows (related to) a nurse can be attended to before you. I do not know any nurse, so anytime I come for antennal care I always go home late. I think they have to talk to the nurses to treat everybody equally. Female, 19 years and pregnant

Judgemental attitudes. In addition to disrespect for adolescents and discrimination emerged judgemental attitudes from health care providers. Adolescents stated that some health care providers judged them, especially pregnant adolescents and called them names like "bad girl". This does not promote adolescent-friendly care and therefore has to be discouraged:

One day I requested for a condom from one of the nurses and she told me that I am a bad boy and that what I was going to do with a condom. She told me to concentrate on my studies and stop chasing small girls. Male, 19 years

I remember that on my first antenatal visit some of the nurses were reluctant to attend to me. One nurse asked me why I got pregnant at this tender age and that I was a "bad girl" who did not pay heed to my parents' and teachers' advice. Female, 16 years

Personal-level barriers. In addition to the above-mentioned barriers, it emerged that adolescents had their personal challenges that restricted them from accessing health services. Three sub-themes emerged under this major theme and include fear, inadequate information and financial constraints.

Fear. Adolescents claimed that some of their peers were afraid to visit the AC. They perceived the fear of not being welcomed by health care providers as a barrier to accessibility. Adolescents indicated that some of their peers have similar perceptions which discourage them from accessing health care services:

Before I visited the adolescent clinic, I was afraid that the nurses would not be comfortable discussing sex-related issues with me. But after visiting the clinic that negative thinking disappeared. There are "young" people like me in the community who have similar perceptions. Male, 18 years

Lack of information. Lack of information also emerged as a barrier to accessing adolescent health services. It was revealed that some adolescents did not visit the ACs because they were not aware of its existence:

Some of our peers do not visit the adolescent clinic because they do not know it exists in this community. For instance, I have lived in this community for long but never heard of the adolescent clinic until a nurse from the clinic visited our school to educate us on adolescent health issues. I believe there are other adolescents like me who have not heard about the clinic. Female, 17 years 
JHR

33,3

204

Financial challenges. At last, adolescents stated financial challenges as one of the factors that discouraged them from using the $\mathrm{AC}$ frequently. Adolescents who stayed far from the ACs complained about the high cost of transportation:

I stay very far from the where the clinic is located and therefore cannot walk to the clinic. I have to "pick" two trotros (commercial transport) before I can get here (clinic). [...] I am not working (employed) and therefore cannot afford trotro all the time. Female, 16 years

\section{Discussions and implications}

Consistent with extant studies, negative provider attitudes were found as a major barrier to using adolescent health services[25-27]. Adolescents are more likely to seek or continue with care if they perceive providers to be adolescent friendly[16]. In addition, adolescents will not hesitate to disclose sensitive information about their health to providers who are non-judgemental[28]. Therefore, there is a need for health care managers or supervisors of the ACs to reinforce or encourage adolescent-friendly attitudes among adolescent health care providers. This can be achieved through the use of incentives, negative reinforcement or on the job training[12].

Another barrier to accessibility and utilisation in this study was the lack of adequate physical space and privacy at the ACs[5, 13, 1.29-31]. Adolescents attach much importance to their privacy and may not access health services if they perceive that health facilities cannot guarantee them adequate privacy[15, 32]. In addition, shortage of medicines and supplies, long waiting times and inconvenient operating hours were also found to be barriers to using adolescent health services. These have been documented by prior studies[13, 25, 29, 33, 34]. Improving resource availability in health facilities has been found to be significantly associated with adolescents' utilisation of health services[12, 35]. Moreover, the poorly equipped nature of the adolescent libraries was also found to be a barrier to accessing adolescent health information. Moreover, adolescents expressed concerns about the scanty nature of the health information materials. These findings suggest that to improve access to adolescent health services, it would be necessary for health care managers to consider expanding and resourcing the ACs coupled with reducing patient waiting time and reviewing the operating hours.

Furthermore, negative perceptions of community members and low parental support were found to be major barriers to accessing ACs. Studies have confirmed disapproval by parents and community members as a barrier to adolescents' access to reproductive health services $[16,25]$. Chandra-Mouli et al.[36] found poor community support for adolescents' contraceptive use in LMICs. Adolescents are mostly not independent, and therefore may require the approval or consent of their guardians or parents before they can access health services. In this regard, involving community leaders and parents in the decisions regarding adolescent health care is ideal. Denno and Hoopes[37] recommended that effective approaches should be implemented to enhance community acceptance of adolescent health programmes.

Last but not the least, the findings revealed that adolescents' access to health services is restricted by personal challenges such as fear, and lack of information about adolescent health facilities. Prior studies found fear, stigma, shame and lack of information as major barriers to accessibility and utilisation of adolescent-friendly health care in Zambia, Vanuatu and South Africa[12, 16, 38]. This study suggests that health interventions geared toward improving accessibility and utilisation of health services among adolescents should consider awareness creation and means of allaying the fears of adolescents through outreach activities in schools and communities.

\section{Conclusion}

Improving access to primary health care to all manner of persons is a global dream. However, the realisation of this dream may be delayed if efforts are not made to reach out to 
underserved populations like adolescents. The purpose of this study was to explore barriers to accessibility and utilisation of adolescent health services. It was found that adolescents encountered negative provider attitudes, inadequate resources in adolescent health facilities, weak parental and community support for adolescent health interventions and personal constraints. This study provides useful information for health policymakers and practitioners, especially those whose remit includes adolescent health. That notwithstanding, the study has limitations such as the research approach. Qualitative studies are not ideal for generalisations, therefore, a generalisation of the findings should be used with caution.

\section{References}

1. Nair M, Baltag V, Bose K, Boschi-Pinto C, Lambrechts T, Mathai M. Improving the quality of health care services for adolescents, globally: a standards-driven approach. J Adolesc Health. 2015 Sep; 57(3): 288-98. doi: 10.1016/j.jadohealth.2015.05.011

2. World Health Organization [WHO]. A standards-driven approach to improve the quality of healthcare services for adolescents. Geneva: WHO; 2015.

3. Zhang L, Jejeebhoy S, Shah I, Zhang L, Hsia J, Im-Em W. Access to contraceptive services among unmarried young people in the north-east of China. Eur J Contracept Reprod Health Care. 2004 Sep; 9(3): $147-54$.

4. Tafuri S, Martinelli D, Germinario C, Prato R. Determining factors for condom use: a survey of young Italian adults. Eur J Contracept Reprod Health Care. 2010 Feb; 15(1): 24-30. doi: 10.3109/ 13625180903427683

5. Onokerhoraye AG, Dudu JE. Perception of adolescents on the attitudes of providers on their access and use of reproductive health services in Delta State, Nigeria. Health. 2016; 9(1): 88-105.

6. World Health Organization [WHO]. Global accelerated action for the health of adolescents (AA-HA!): guidance to support country implementation. Geneva: WHO; 2017.

7. Neal S, Matthews Z, Frost M, Fogstad H, Camacho AV, Laski L. Childbearing in adolescents aged 12-15 years in low resource countries: a neglected issue. New estimates from demographic and household surveys in 42 countries. Acta Obstet Gynecol Scand. 2012 Sep; 91(9): 1114-8. doi: 10.1111/j.1600-0412.2012.01467. Epub 2012 Jul 12.

8. World Health Organization [WHO]. Adolescent pregnancy: adolescence is a time of opportunity during which a range of actions can be taken to set the stage for healthy adulthood: fact sheet. Geneva: WHO; 2014.

9. United Nations International Children's Emergency Fund [UNICEF]. For every child end aids - seventh stocktaking report. New York, NY: UNICEF; 2016.

10. Rickwood DJ, Deane FP, Wilson CJ. When and how do young people seek professional help for mental health problems? Med J Aust. 2007 Oct 1; 187 (S7): S35-9.

11. Gulliver A, Griffiths KM, Christensen H. Perceived barriers and facilitators to mental health help-seeking in young people: a systematic review. BMC Psychiatry. 2010; 10: 113-22. doi: 10.1186/1471244X-10-113

12. Geary RS, Gómez-Olivé FX, Kahn K, Tollman S, Norris SA. Barriers to and facilitators of the provision of a youth-friendly health services programme in rural South Africa. BMC Health Serv Res. 2014 Jun 16; 14: 259-67. doi: 10.1186/1472-6963-14-259

13. Lim SW, Chhabra R, Rosen A, Racine AD, Alderman EM. Adolescents' views on barriers to health care: a pilot study. J Prim Care Community Health. 2012 Apr 1; 3(2): 99-103. doi: 10.1177/ 2150131911422533

14. Tangmunkongvorakul A, Banwell C, Carmichael G, Utomo ID, Seubsman S.A., Kelly M, et al. Use and perceptions of sexual and reproductive health services among young northern Thai people. Southeast Asian J Trop Med Public Health. 2012 Mar; 43(2): 479-500. 
15. Sogarwal R, Chandra M, Mehra S. Youth friendly health services and role of outreach activities to improve access to services. Open J Prev Med. 2013; 3(2): 191-8.

16. Kennedy EC, Bulu S, Harris J, Humphreys D, Malverus J, Gray NJ. "Be kind to young people so they feel at home”: a qualitative study of adolescents' and service providers' perceptions of youthfriendly sexual and reproductive health services in Vanuatu. BMC Health Serv Res. 2013 Oct 31; 13: 455-67. doi: 10.1186/1472-6963-13-455

17. Ghana Health Service. Family health annual report. Accra: Family Health Division; 2015.

18. Dialy Graphic. 609 teenage pregnancies recorded in Tema. 2017. [cited 2017 Mar 23]. Available from: www.graphic.com.gh/news/general-news/609-teenage-pregnancies-recorded-in-tema.html

19. Ghana Statistical Service. 2014 Ghana demographic and health survey. Accra: Ghana Statistical Service; 2015. [cited 2017 May 22]. Available from: https://dhsprogram.com/pubs/pdf/fr307/ fr307.pdf

20. Biddlecom AE, Singh S, Munthali A. Adolescents' views of and preferences for sexual and reproductive health services in Burkina Faso, Ghana, Malawi and Uganda. Afr J Reprod Health. 2007 Dec; 11(3): 99-110.

21. Esantsi SF, Onyango F, Quansah Asare G, Kuffour EO, Tapsoba P, Birungi H. Understanding the reproductive health needs of adolescents in selected slums in Ghana: a public health assessment. Accra: Population Council; 2015 [cited 2017 February 22]. Available from: www.popcouncil.org/ uploads/pdfs/2015STEPUP_RHAdolGhana.pdf

22. Ghana Statistical Service. 2010 population and housing census: district analytical report. Accra: Ghana Statistical Service; 2014.

23. Maguire M, Delahunt B. Doing a thematic analysis: a practical, step-by-step guide for learning and teaching scholars. AISHE-J. 2017; 9(3): 3351-4.

24. Braun V, Clarke V. Using thematic analysis in psychology. Qualitative Res in Psychology. 2006; 3(2): 77-101.

25. McPherson A. ABC of adolescence: adolescents in primary care. BMJ. 2005; 330(7489): 465-7

26. Ensign J, Panke A. Barriers and bridges to care: voices of homeless female adolescent youth in Seattle, Washington, USA. J Adv Nurs. 2002 Jan; 37(2): 166-72.

27. Lindberg C, Lewis-Spruill C, Crownover R. Barriers to sexual and reproductive health care: urban male adolescents speak out. Issues Compr Pediatr Nurs. 2006 Apr-Jun; 29(2): 73-88.

28. Erulkar AS, Onoka CJ, Phiri A. What is youth-friendly? Adolescents' preferences for reproductive health services in Kenya and Zimbabwe. Afr J Reprod Health. 2005 Dec; 9(3): 51-8.

29. Senderowitz J, Hainsworth G, Solter C. A rapid assessment of youth friendly reproductive health services. Watertown, NY: Pathfinder International; 2003.

30. Agampodi SB, Agampodi TC, Piyaseeli U. Adolescents perception of reproductive health care services in Sri Lanka. BMC Health Serv Res. 2008 May 3; 8: 98-106. doi: 10.1186/1472-6963-8-98

31. Coker TR, Sareen HG, Chung PJ, Kennedy DP, Weidmer BA, Schuster MA. Improving access to and utilization of adolescent preventive health care: the perspectives of adolescents and parents. J Adolesc Health. 2010 Aug; 47(2): 133-42. doi: 10.1016/j.jadohealth.2010.01.005

32. Ambresin A-E, Bennett K, Patton GC, Sanci LA, Sawyer SM. Assessment of youth-friendly health care: a systematic review of indicators drawn from young people's perspectives. J Adolesc Health. 2013 Jun; 52(6): 670-81. doi: 10.1016/j.jadohealth.2012.12.014

33. Tilson EC, Sanchez V, Ford CL, Smurzynski M, Leone PA, Fox KK, et al. Barriers to asymptomatic screening and other STD services for adolescents and young adults: focus group discussions. BMC Public Health. 2004 Jun 9; 4: 21-9.

34. Boydell KM, Pong R, Volpe T, Tilleczek K, Wilson E, Lemieux S Family perspectives on pathways to mental health care for children and youth in rural communities. J Rural Health. 2006; 22(2): 182-8.

35. Schriver B, Meagley K, Norris S, Geary R, Stein AD. Young people's perceptions of youth-oriented health services in urban Soweto, South Africa: a qualitative investigation. BMC Health Serv Res. 2014 Dec 5; 14: 625-32. doi: 10.1186/s12913-014-0625-y 
36. Chandra-Mouli V, Chatterjee S, Bose K. Do efforts to standardize, assess and improve the quality of health service provision to adolescents by government-run health services in low and middle income countries, lead to improvements in service-quality and service-utilization by adolescents? Reprod Health. 2016 Feb 6; 13: 10-8. doi: 10.1186/s12978-015-0111-y

37. Denno DM, Hoopes AJ, Chandra-Mouli V. Effective strategies to provide adolescent sexual and reproductive health services and to increase demand and community support. J Adolesc Health. 2015; 56 (1): S22-S41. doi: 10.1016/j.jadohealth.2014.09.012

38. Mmari KN, Magnani RJ. Does making clinic-based reproductive health services more youth-

Access to and use of adolescent health friendly increase service use by adolescents? Evidence from Lusaka, Zambia. J Adolesc Health. 2003 Oct; 33(4): 259-70.

\section{Corresponding author}

Emmanuel Anongeba Anaba can be contacted at: emmaanaba24@gmail.com

For instructions on how to order reprints of this article, please visit our website: 